of interest in the problems of the consumer, and the present volume is a comprehensive study of the difficulties that beset him (or her, as the case may be) in obtaining the desired goods at the lowest price.

The author deals first with the buying habits of the consumer and the structure of the retail market, in which connexion some interesting statistics are given of the comparative costs of marketing commodities by various methods and through various types of shop. Sections on instalment buying and retailers' price policy lead up to the most valuable part of the book, the section on "Market Devices as Aids to Consumer-buyers". After reading this account of the salesmanship, labelling, packaging, guaranteeing, branding and advertising of goods, one is forced to the conclusion that tho main purposo of all these 'market devices' is the deception of the consumer. The inadequacy of legislative protection has given rise to such organizations as Consumers' Research, which seeks to provide confidential information on the relative merits of advertised or branded goods.

R. WV.

\section{A Short History of Science}

By Dr. F. Sherwood Taylor. Pp. xiv $+320+14$ plates. (London and Toronto: William Heinemann, Ltd., n.d.) 8s. $6 d$. net.

A $N$ attempt to cover the history of science in A some three hundred pages is bound to produce a result which can be criticized from one angle or another. The present book is probably as good an account as is possible in the space. The earlier chapters are of a more general character and will perhaps appeal most to the general reader, but even in the account of the later period, when the material is overwhelming, the author has managed to select with good judgment and to convey the story in a connected fashion. The book is one which should have a wide appeal. The interesting illustrations require special praise.

\section{PhILOSOPHY}

On Understanding Physics

I3y Prof. W. H. Watson. Yp. xii + 146. (Cambridge : At the University Press, 1938.) 7s. 6d. net.

TN this work, Prof. Watson thinks aloud about some 1 fundamental concepts and theories of modern physics. He uses for this purpose the analytical method favoured and practised by Dr. Wittgenstein, with the result that many questions, such as those of atomic mechanies and electricity, regarded mainly as mathematical or physical, resolve themselves into logical problems. There is no doubt that science does benefit from a systematic clarification of its language. But is it not going beyond this achieve. ment to separate science entirely from philosophy? Language and symbols cannot go beyond themselves, so to speak, in representing the world of the physicist ; but that should be no reason for denying value to what is represented. Such a value, of course, cannot be found within the restricted world of linguistic expression, especially in so far as it is applied to technically physical concepts. That is why Prof. Watson's conclusions from his discussion of the idea of substance (ch. v) seem to be beside the point. Nevertheless, the new ground broken in his book makes it a most useful contribution to the philosophy of Nature.

T. $\mathbf{t}$.

\section{Symbolism and Belief}

By Edwyn Bevan. (Gifford Lectures.) Pp. 391. (London: George Allen and Unwin, Ltd., 1938.) 15s. net.

7 HE philosophy of symbols has become prominent lately through the efforts of mathematical logicians. But it is not with that aspect of the subject which the book under review deals. The author is concerned with the relations between symbolism and religious beliefs. The very character of the data of revelation makes it necessary for man to uso symbols for their interpretation and communication. In this respect Mr. Bevan performs a very useful task in explaining, with the support of an amazing amount of scholarship, the purpose of symbolism in these matters. His points would have been strengthened, however, by a bolder theory of analogy. As it is, his book enlightens us, but has little drive in it to guide us towards those truths which underlie his theme.

T. G.

\section{PHYSICS}

Heat and Thermodynamics

An Intermediate Textbook for Students of Physics, Chemistry and Engineering. By Prof. Mark W. Zemansky. Pp. xii +388. (New York and London : McGraw-Hill Book Co., Inc., 1937.) 24s.

THIS text is well suited to the needs of first-year 1 honours students in physics and to students taking a graduate course in engineering. Experimental methods are cut down to the shortest possible presentation consistent with clearness, and modern mothods aro in most instances selected. Thus, the description of the time-honoured experiments of Joule and of Rowlands for the determination of $J$ is cut down to a few words, and Callendar and Barnes, Jaeger and Steinwehr, and Laby and Hercus appear in their place. Forbes and Angström dis. appear, and a short account of the modern simple methods for conductivity determinations reigns instead.

Of the two partners in the title, thermodynamics has the lion's share of the space. The treatment is elementary, detailed and satisfactory; unavailable energy is correlated with entropy, and a number of special problems are discussed, including the phase rule. Applications of the Helmholtz and Gibbs functions are made, and a special chapter is devoted to the steam-engine and the refrigerator. Newton's law of cooling is deduced from the fourth power law as holding for small temperature excesses. The fact is, that Newton's law, in the circumstances in which it was established by Newton (forced convection), holds, as he showed it to hold, for temperature excesses of some hundreds of degrees. 